\title{
Baroja e Hispanoamérica
}

$\mathrm{A}^{\mathrm{N}}$ las numerosas obras que nos ha legado Pío Baroja hay constantes de forma $\mathrm{y}$ de fondo discernibles para todo lector. Entre ellas se encuentran dos que constituyen rasgos distintivos de los escritos de este autor: la cantidad abrumadora de personajes que participan en el desarrollo de la narración y las exteriorizaciones que hace el novelista de sus íntimos sentimientos, de sus arraigadas convicciones y de sus pasajeros caprichos. La abigarrada multitud de individuos que entran en la acción, en calidad de principales o de secundarios, tienen un objetivo bien definido: comunicar al lector la impresión que posee Baroja de que la vida cotidiana no es otra cosa que un complicado engranaje, muchas veces descompuesto o ilógico, en el cual se halla encasillada la existencia del hombre. Esta visión integral de la sociedad no es, sin embargo, del todo objetiva porque la vida de los personajes no es exclusivamente suya, sino que depende, por el contrario, de los antojos que impulsan a Baroja, de las creencias que él sustenta como ideales de vida y de ciertos sentimientos de simpatía o antipatía que le parecen haber operado en la gestación y desarrollo de los rasgos distintivos del hombre como ente social. De esta concepción de la novela resulta que los personajes son, por una parte, integrantes de un conjunto social, tal como lo ve el autor y, por otra, expresión de la crítica favorable o adversa que esa sociedad y sus elementos constitutivos merecen al escritor.

Esta manera de concebir y de realizar el plan novelístico tiene una fuerza expansiva tan irresistible que Baroja necesita no sólo varios tomos para llevar a cabo su cometido, sino que debe explayarse en prolongadas digresiones a fin de no 
dejar la menor huella de duda acerca de su ideología. Entre los muchos ejemplos que se pueden citar, a manera de ilustración de lo que venimos sosteniendo, los más claros son los suministrados por la novela Paradox, rey. 1 I a forma dialogada que emplea el autor en esta obra le impide entregarse a las disquisiciones que tanto le seducen y que tanto abundan en otras novelas. Por eso es que, a veces para dar libre curso al caudal de sus opiniones, sencillamente interrumpe el relato y hace hablar al AUTOR. Tal es la función que llenan el Elogio sentimental del Acordeón, el Elogio metafísico dt la Destrucción, el Elogio de los viejos caballos del Tíovivo y numerosos párrafos en que dialogan animales o elementos de la naturaleza.

Los personajes, por lo demás, se expresan y se desenvuelven como Baroja quiere que lo hagan para que mejor ilustren su propio pensar y sentir acerca de la sociedad en que se mue. ven. Más aun, las digresiones refuerzan los conceptos que el autor ha deseado encarnar en sus personajes, a la vez que preparan propiciamente el terreno en que queda cimentada toda una posición ideológica. Sólo así el lector logra adaptarse a la dogmatización que Baroja se esfuerza por predicar a toda costa.

Las simpatías y antipatías del novelista, así como sus postulados principales, tan volubles en la historia de sus ideas, como enfáticos al ser presentados por primera vez en el curso de un relato, además de reflejarse en la novela con meridiana claridad, quedan completamente al desnudo en los numerosos ensayos que año tras año fué entregando a las prensas por espacio de más de media centuria.

Como parte integrante de las novelas y como tema de algunos de los ensayos de Baroja se encuentran los hispanoamericanos y la tierra de la cual proceden, ambos formando parte del elenco de las antipatías que más disgustan y exasperan al autor. Con el objeto de destacar la actitud del escritor vasco hacia Hispanoamérica y sus habitantes, nos hemos circunscrito en este estudio a tres de sus obras más conocidas:

1 Paradox, rey. Edited with Introduction, Notes and Vocabulary by Claude E. Anibal (New York, 1937). 
Paradox, rey, Juventud, egolatria ${ }^{2}$ y Las horas solitarias 3 porque ellas reflejan claramente los sentimientos personales del autor a la vez que corroboran con objetividad indiscutible la tesis que nos esforzamos por demostrar.

En Paradox, rey, conocemos al general Pérez y a su hija Dora, procedentes de Venezuela y a la sazón alojados en el Hotel Continental de Tánger. Entran en la acción en circunstancias de que los protagonistas se disponen a emprender el famoso viaje de colonización al Cananí, tema y asunto que ocupan lo central de la novela. Mientras duran los preparativos de la partida, algunos de los futuros colonos se conciertan para hacer una excursión al Cabo Espartel. El general, quien en esos momentos se encuentra jugando al billar con su hija y unos amigos, se percata de la proyectada excursión, pero no se interesa mayormente por incorporarse al grupo porque no desea fatigarse haciendo un viaje a caballo que, según se le informa, va a durar por lo menos dos horas.

La primera impresión que produce el general es, pues, la de ser un individuo algo sedentario, más dado a la molicie que a la actividad que debiera demostrar como buen militar. El temor al cansancio, indudablemente le lleva a la inactividad física, pecado capital en el credo de Baroja, para quien el hombre de acción constituye el ideal más perfecto a que se debe aspirar en la vida.

La caracterización de Pérez, sin embargo, no queda aquí detenida puesto que el autor, de inmediato pone en sus labios otras palabras muy sugerentes del modo de ser americano, según Baroja: "Es mucho; hay para fatigarse... y eso que yo estoy acostumbrado. (A PARADOX) Ya ve usted, mi amigo, en más de cien combates que he tomado parte". (Paradox, pág. 14).

La disculpa resulta tan inverosímil que sin mayores explicaciones quedamos convencidos de su completa falsedad. No podemos olvidar que lo primero que se le ocurrió pregun1948).

2 Juventud, egolatria, en Obras completas de Pio Baroja, tomo V (Madrid, 3 Las boras solitarias, en Obras completas de Pio Baroja, tomo V (Madrid, 1948). 
tar al americano, cuando oyó lo de la excursión, fué la distancia a que se hallaba el Cabo Espartel. Tampoco se nos olvida que su espontánea reacción ante las condiciones en que iba a realizarse el viaje fué la de que un par de horas a caballo "es mucho" pues con ello "hay para fatigarse". Es, por lo tanto, increíble que esté acostumbrado a esas cosas, como afirma, y parece más lógico presumir que lo que quiso decir era que "estaba acostumbrado". Se nos hace dificilísimo convenir con su afirmación de que ha participado en "más de cien combates", si consideramos que una batalla siempre demanda algo más vigor que el exigido por una cabalgata de relativamente poca duración. Además, la apresurada inoportunidad con que el general saca a relucir su actuación refleja que es o un intolerable fanfarrón o un consumado embustero. Por otra parte, si aceptáramos la aseveración que analizamos, nos quedarían aun las dudas de si aquellos combates en verdad requirieron alguna pericia, si los que confiaron a tal jefe militar la tarea de combatir sabían seleccionar a sus soldados o si el enemigo demandaba algún despliegue de destreza física o intelectual. En el mejor de los casos, para ser generosos, quizás debiéramos pensar que el general fué un gran estratega en sus buenos tiempos y que en la actualidad se encuentra en decadencia. Nos inclinaríamos a aceptar este modo de juzgar, si no fuera que las profundas llagas espirituales que exhibe nuestro personaje en el curso del relato ejemplifican hábitos muy arraigados, limitaciones intelectuales casi ingénitas y desequilibrio emocional lindante en lo obsesivamente patológico. Acaso para probar mejor su punto de vista, Baroja hace que nuestro general se acople a los excursionistas y que durante el recorrido despliegue todos los rasgos negativos y taras de su caráter.

Contrasta con la personalidad de Pérez, la de Dora, su hija. La joven no sólo se decide sin trepidar a ir al Cabo Espartel, sin importarle los obstáculos e incomodidades que han hecho titubear a su padre, sino que nos convence de que es admirable por algunas de las virtudes que adornan su persona. Magnífico ejemplo es aquél en que demuestra su pericia al dominar una cabalgadura que tiene fama de traviesa. Cuando la americana manifiesta al médico su deseo de montar 
la jaca de él, éste cree que no es sino mera jactancia femenina $\mathrm{y}$ así se lo manifiesta a su amiga. Dora, sin mayores preámbulos, da pruebas de su afirmación, cambiando ella misma la silla de montar y sometiendo al animal al control que sólo se esperaría de un excelente jinete. El mismo médico se apresura a confesar que no habría sido capaz de permanecer en el animal, cuando al cruzarse un borriquillo en el camino, la jaca se encabrita $y$ se pone sobre las patas traseras.

(El animal sigue dando brincos. La americana afloja las riendas y, cuando el caballo baja la cabeza, le da con toda su alma un fustazo. Bota el caballo, y comienza a galopar frenéticamente. El sombrero de la americana cae sobre su espalda, y caballo y jinete desaparecen al trasponer una colina. Poco después se presenta DORA; el caballo viene sudando, ya vencido) (Paradox, pág. 16).

¿Trata Baroja de contrastar dos generaciones, una decadente y falsa con la otra vigorosa, promisora y apta? Nos inclinamos a creer que sí, porque mientras Dora no deja dudas de la destreza de que ha hablado, su padre sigue poniendo de manifiesto su absoluta incapacidad para haber sido autor de las proezas de que hace alarde. Y recordemos, de paso, que Dora se va al Cananí con los nuevos colonos, en tanto que su padre se queda sumido vegetando en el anonimato a que $\mathrm{Ba}-$ roja condena a los personajes insignificantes.

Al llegar al Cabo Espartel, el general Pérez continúa retratándose de cuerpo entero. Es él quien apresura el lamentable experimento que su amigo, el médico, desea ralizar emborrachando a un gallo. El americano considera que no habrá nada más gracioso que ver intoxicada a la indefensa ave. Por eso ayuda a cazarla para no aplazar las perspectivas de presenciar tan original espectáculo. La crueldad del acto es tal, que Baroja no sólo habla por boca del gallo y de Paradox, sino que hasta aprovecha los paréntesis del diálogo para expresar su íntimo modo de sentir.

EL GALLO. ¿Qué horrible veneno me han dado estos extranjeros ?... QQué extrañas ideas cruzan por mi mente! ...Siento locos impulsos, deseos estrambóticos... Q Que Dios 
castigue a estos desconocidos que así turban el reposo espiritual de un buen padre de familia!

(PARADOX se aleja seguido de YOCK, indignados ambos al ver la tropelía que han cometido con el GALLO...)

Cuando llega el momento de servirse el cuz-cuz preparado por el moro Hachi Omar, el médico asegura a los comensales que ese guiso sabe mejor cuando se le come con la mano. Dora apunta que tales modales serían impropios en presencia de una dama, pero su padre insiste en que su amigo proceda en la forma sugerida porque eso es lo único que le hace falta para imitarlo. Por segunda vez, si recordamos que la idea de emborrachar al gallo to fué del general, Pérez depende en gran medida de las sugerencias de otros para satisfacer sus pequeños placeres personales. Esta disposición del venezolano para seguir a ciegas las iniciativas de otras personas es particularmente visible en los momentos en que quiere proporcionarse entretenimientos para él agradables, pero a todas luces ordinarios y groseros para los demás.

A estas alturas del relato colegimos otros de los móviles que han inducido al americano a unirse a los excursionistas. Sin la compañía de sus amigotes, en especial del médico, el general se habría aburrido soberanamente en el Hotel Continental o tal vez, al comprobar que todos se iban de viaje, se sintió arrastrado por el entusiasmo de la comitiva. Sea cual fuere la alternativa por la cual optemos, nuestro personaje acusa una falta absoluta de iniciativa y echa de ver su total dependencia de los demás.

La presencia de Pérez durante la excursión se convierte en una pesada carga para todos los integrantes del grupo. Cuando Paradox manifiesta deseos de acercarse a unas peñas que se divisan a lo lejos, y Hachi Omar le contesta que se hace tarde, el general "que ha participado en cien combates" se aferra a este buen pretexto, insistiendo en que es mejor no aventurarse a dar tal paso pues podrían perderse en la oscuridad. No tardamos, por otra parte, en percatarnos de que, además del miedo a extraviarse, el americano carece de las fuerzas físicas necesarias por encontrarse lamentablemente borracho para acceder a los deseos de Paradox. 
Desde este momento en que la ebriedad se apodera de la mente del general venezolano, su conducta se hace más y más intolerable: deben cuidarle para que guarde el equilibrio, irrumpe en explosiones de chocante euforia y da, una y otra vez, con insistente majadería, en el gastado e inútil tema de que la América es superior a Europa:

EL MEDICO. Mi general, guarde usted el equilibrio. Me parece que está un poco zanana.

EL GENERAL. ¿Cómo dice? ¿Zanana?... ¡Ay qué macanudo!

EL INGLES. Está intoxicado; bebido completamente.

(...Todos van cabalgando silenciosos, menos el GENERAL, que, rezagado de la comitiva, no para de hablar).

EL GENERAL. (tartamudeando, a PARADOX). He estado en más de cien batallas, mi amigo, ¿sabe? Y no como las de Europa, sino algo más serias, más científicas. Créame, mi amigo, en todo está América por encima de Europa; hay que americanizar al mundo.

EL MEDICO (al INGLES, que se ha quedado retrasado unos pasos). ¿Quiere usted que le demos un susto al general?

EL INGLES. ¡Oh mucho, mucho! Está muy pesado, muy fastidioso.

(E1 MEDICO se adelanta como si no pudiera refrenar su cabalgadura. Los caballos de PARADOX y del GENERAL se espantan y se ponen a dar botes, y el GENERAL cae al suelo...) (Paradox, págs. 19-20).

Compárese, sólo de pasada, esta escena con la otra que ya hemos mencionado en que Dora domina a la jaca. El general queda muy por debajo de la destreza de su hija. ¿Trata Baroja una vez más de contrastar la idiosincrasia de dos generaciones?

En suma, Pérez es un sujeto fanfarrón, embustero e incapaz de convencer a nadie con su odiosa jactancia. La carencia de originalidad y de iniciativa, ciertamente le sumirían no sólo en la imposibilidad de labrarse situaciones que siquiera le estimularan en su absurdo modo de divertirse, sino que, si tuviera que depender de sus propias fuerzas físicas y espirituales, caería en el más deplorable e integral estado de descomposición.

La sombria personalidad de este militar, que es una de 
las creaciones más deprimentes en la galería barojiana, no es mero accidente, pues en otras obras, como por ejemplo en Las tragedias grotescas, ${ }^{4}$ los americanos tampoco son en modo alguno más simpáticos que el general de Paradox, rey. No es dable creer, por otro lado, que todos ellos sean meros recursos de que ha echado mano el escritor para crear una situación humorística que deleite al lector. Obedecen, al contrario, a un plan satírico premeditado del autor y son reflejo inequívoco de las profundas convicciones que ha estampado con toda seriedad en Juventud, egolatria y en Las horas solitarias, obras publicadas años más tarde que las novelas a que hemos aludido: la primera es del año 1917 y la segunda de 1918, en tanto que Paradox, rey aparece en 1906 y Las tragedias grotescas en 1907. La permanencia ideológica del autor es indiscutible en estos doce años de su vida en que contaba entre 34 y 46 de edad, época de la existencia de un hombre en que ya se le concibe con ideas bien formadas y razonadas. No se trata, como bien pudiera pensarse, de una antipatía de Baroja por los americanos de las zonas tropicales o de determinados países cuyo colorido y efusividad acaso chocara al vasco, sino de un prejuicio general que abarca a todos los americanos sin distinciones de ninguna clase.

Paralelamente sucede, que, a veces, en un pueblo nuevo se reúne toda la torpeza provinciana, con la estupidez mundial, la sequedad y la incomprensión del terruño con los detritus de la moda y de las majaderías de las cinco partes del mundo. Entonces brota un tipo petulante, huero, sin una virtud, sin una condición fuerte. Éste el tipo del americano. AMERICA ES FOR EXCELENCIA EL CONTINENTE ESTUPIDO.5

El americano no ha pasado de ser un mono que imita.

Yo no tengo motivo particular de odio contra los americanos; la hostilidad que siento contra ellos es por no haber conocido a uno que tuviera un aire de persona, un aire de hombre...

Esta impresión de hombre sereno, tranquilo, es la que no dan los americanos nunca; uno se nos aparece como un impulsivo atacado de furia sanguinaria, el otro con una va-

4 Las tragedias grotescas, en Obras completas de Pio Baroja, tomo V (Madrid, 1.948). 
nidad de bailarina, el tercero con una soberbia ridícula. (Juventud, egolatría, págs. 213-214).

La declaración de Baroja es por demás explícita para merecer mayores comentarios y nos permite comprender la causa de que los americanos hayan aparecido en sus obras siguiendo muy de cerca el perfil inconfundible del general criollo cuya fisonomía acabamos de bosquejar. Los defectos que el conocido autor vasco descubre en los hispanoamericanos se dan uno a uno en la persona del militar venezolano y demuestran que los prejuicios que por el año 1906 abrigaba Baroja contra sus hermanos de América perduraban en 1917, al aparecer su renombrado ensayo.

Un año más tarde, en 1918, en Las horas solitarias, don Pío escribe de nuevo sobre la América Hispana en un capítulo intitulado "Los españoles de Amérca". Insiste, una vez más, en su actitud de agresivo distanciamiento, haciendo constar que mientras más desligados se hallen España y los españoles del nuevo continente, mayor será la satisfacción y sensación de alivio para todos en la península.

Los españoles hemos notado que mientras hemos vivido con la carga de América, hemos ido de mal en peor. Al soltarla es cuando ha comenzado a normalizarse la vida en España. Tarde o temprano, el pequeño lazo que nos une con América se ha de romper. Cuanto más pronto, mejor...

Lo que a mí me irrita de los hispanoamericanos es lo mal que legitiman su modernidad. No son capaces de crear una Universidad especializada ni de tener grandes industrias, grandes inventores o grandes ingenieros, ni de lanzar una utopia al mundo; son negociantes en pequeño, y cuando quieren hacer algo espiritual, hacen versos o escriben una sociología traducida del francés. Están a la altura de lo peor que hay entre nosotros: del señorito...

A estos americanillos les asombra y les molesta que en España pueda haber gentes de pensamiento audaz, capaces de sobrepasar sus ideales. Ellos creen que con la República y la democracia y cuatro o cinco cantatas latinociudadanas, con las que nos están aburriendo desde hace muchós años, han llegado al término de todas las posibilidades. $\mathrm{Y}$ en esto se engañan. (Las horas solitarias, págs. 260-261).

No estará demás consignar en este trabajo que los juicios de Baroja sobre la literatura hispanoamericana son igual- 
mente radicales, demoledores y arbitrarios. No es del caso en este estudio refutar las imputaciones de don Pío contra América y los americanos, labor que le corresponderá a algún especialista en las llamadas ciencias sociales, en las que habrá un abundante acopio documental. Quedarían también por averiguar, aunque esto resulte ardua tarea, los motivos que indujeron al novelista vasco a formarse estas ideas de los criollos. ¿Fueron sus lecturas, sus amigos americanos, la derrota de España causada por las colonias de este continente, los conceptos tradicionales acerca de los indianos? Tampoco podemos responder con absoluta certidumbre. Lo que sí quisiéramos indicar es que en Las horas solitarias hay unos renglones que parecen muy sintomáticos y que quizás ayuden a desentrañar un rencor oculto en el corazón de Baroja:

Dicen que yo soy gayego y no vasco; que he sido mozo de tahona; que hablo mal de la Argentina porque cuando estuve en Buenos Aires pedí un destino en una casa de comercio y no me lo dieron...

Los que me conocen ya saben cómo soy; los que no me conocen es lo mismo que piensen lo que quieran; los que saben que yo no he pasado el Atlántico no van a creer que porque no me dieron un empleo en Buenos Aires he hablado con rudeza de los amexicanos.

Como digo, no voy a contestar a La Crítica...

(Las horas solitarias, págs. 259-260).

¿Hay algo de resentimiento en Baroja? Difícil será asegurarlo categóricamente, si bien no cuesta gran trabajo descubrir el hecho comprobado de que en los renglones precedentes, nada niega de lo que se le ha imputado.

Toda esta actitud negativa del novelista y ensayista vasco nos .lleva también a otra conclusión. Nos inclinamos a manifestar nuestro desacuerdo con los conceptos expresados, acaso con apresuramiento y sin la documentación que hemos reunido, por el conocido crítico español Gonzalo Torrente Ballester, en su artículo "La Generación del 98 e Hispanoamérica". Algunas de sus generalizaciones fundamentales, nos parecen en abierta contradicción con lo expresado por Baroja, representante indiscutible del movimiento noventayochista.

5 Gonzalo Torrente Ballester, "La Generación del 98 e Hispanoamérica", Aubor, № 36, tomo XI, Diciembre, 1948, págs, 505:515. 
Nuestro adiós al imperio colonial, la amarga experiencia del nuevo desastre, tuvo, en este sentido la ventaja de hacer posible un mejoramiento de relaciones, por lo menos con aquellos países que contaban casi un siglo de independencia. Los hombres del 98 son los primeros que sienten a España constreñida a sus límites... Pero son también, por esto, los primeros capacitados para una comprensión de lo hispanoamericano como un hecho nacional y como una serie de hechos singulares, prenacionales. POR LO MISMO, SON LOS PRIMEROS EN VISLUMBRAR, NO SOLO UN POSIBLE ACERCAMIENTO, SINO EL VERDADERO TERRENO EN QUE HA DE PRODUCIRSE6 (Torrente B., pág. 506 del art. cit.)

Todo comentario a tales aseveraciones sería por completo redundante; no es ésa la actitud de Baroja, paladín del 98, a pesar de que él lo niegue, hacia lo hispanoamericano.

Nuestra tesis ha sido poner de manifiesto que existe con frecuencia una relación perfecta entre las convicciones del autor vasco y la forma en que concibe sus personajes. Su ideología y sus antojos se encuentran contenidos, no sólo en las digresiones, sino también en la fisonomía y conducta de sus caracterizaciones, verdaderos títeres de los caprichos del escritor. Más aun, nos queda por indicar que, aunque es cierto que los juicios barojianos muchas veces nos parecen cambiantes y volubles, por otra parte, en el fondo de su mente y en lo profundo de su corazón permanece un residuo de amargura y animosidad instintivamente impulsivas. El crítico no sabe si elogiar o reprobar esta constante espiritual de Baroja; tal es la fuerte vitalidad que posee. El tratamiento de los personajes es chocante, desagradable e hiriente hasta el extremo de engendrar resentimientos y disgustos. Por otra parte hemos de reconocer, con la crítica universal, que las caracterizaciones, desde el punto de vista artístico, son inconfundibles por el singular vigor que prestan a la creación de un mundo barojiano muy especial y fascinante.

Hómero CAstillo, Universidad de Northwestern.

6 Las mayúsculas son nuestras y no de Torrente Ballester. 
